\title{
Calidad del agua residual no entubada vertida por dos parques industriales en la ciudad de Puebla, México
}

Quality of not piped wastewater discharged by two industrial parks in the city of Puebla, Mexico

\author{
María Noemí Bonilla y Fernández \\ Benemérita Universidad Autónoma de Puebla \\ nohemi.bonilla@correo.buap.mx \\ Sonia Emilia Silva Gómez \\ Benemérita Universidad Autónoma de Puebla \\ soemsigo@yahoo.com \\ Carlos Cabrera Maldonado \\ Benemérita Universidad Autónoma de Puebla \\ carlos.cabrera@correo.buap.mx \\ Roberto Carlos Sánchez Torres \\ Benemérita Universidad Autónoma de Puebla \\ rocasato@gmail.com
}

\section{Resumen}

En el estado de Puebla, México se tienen registradas 215140 unidades económicas según el Censo Económico 2009 realizado por el Instituto Nacional de Estadística y Geografía (INEGI), de estas 174 son grandes empresas, 1196 medianas, 5652 pequeñas y 208118 micro empresas, en su mayoría se encuentran ubicadas en los trece parques industriales (PI) de la ciudad, con diversos giros como: textil, metal mecánica, química, embotelladoras, alimentarias, farmacéuticas, etc. Algunas industrias y comunidades descargan sus aguas residuales en forma directa con escaso o nulo tratamiento hacia los cuerpos receptores entre ellos los ríos Atoyac, Alseseca y algunas barrancas. Los 
avances tecnológicos e industriales generados a partir de la segunda mitad del siglo XIX han redundado en múltiples beneficios para los seres humanos, convenientes a las necesidades personales. Sin embargo, estos hechos han crecido junto con un fenómeno cuyo impacto es evidentemente negativo para la subsistencia de la vida en todo el planeta: la contaminación o deterioro del aire, agua, suelo y planta del ambiente debido a la presencia o aumento exagerado de sustancias que perjudican la salud. La evidente contaminación que presentan las aguas residuales no entubadas, generan un importante riesgo para la salud de los habitantes de zonas residenciales cercanas, debido a esta problemática el objetivo de este trabajo de investigación consistió en determinar la calidad del agua de diez efluentes industriales aledaños a los PI 5 de mayo y Puebla 2000, que desembocan a los ríos Atoyac y Alseseca y que posteriormente se almacenan en la presa Manuel Ávila Camacho para que finalmente el agua sea distribuida mediante el canal principal de riego y canales secundarios hacia el Distrito de Riego 030 "Valsequillo" para la irrigación de cultivos agrícolas. La importancia del estudio de la calidad fisicoquímica y microbiológica del agua se debe a su influencia en el suelo y en los productos cosechados, además de los impactos negativos en la salud humana que trae consigo emplear agua contaminada para riego. Se realizaron los análisis mediante la implementación de las metodologías descritas en las Normas Oficiales Mexicanas NMX-Materia de agua. Se determinaron in situ los parámetros: $\mathrm{T}^{\circ} \mathrm{C}$, conductividad eléctrica, materia flotante, $\mathrm{pH}$ y oxígeno disuelto; en el laboratorio: dureza total, cloruros, grasas y aceites, sodio, sulfatos y demanda bioquímica de oxígeno, coliformes fecales, etc. Las concentraciones obtenidas se compararon con los límites máximos permisibles que establecen las Normas Oficiales Mexicanas NOM-001-SEMARNAT-1996 y la NOM-003-SEMARNAT-1997.

Palabras clave: Parques industriales, agua no entubada, barrancas, calidad de agua.

\section{Abstract}

In the state of Puebla, Mexico have been registered 215140 economic units according to the Economic Census 2009 conducted by the National Institute of Statistics and 
Geography (INEGI), of these 174 are large enterprises, 1196 medium, 5652 small and 208118 micro enterprises, as most are located in thirteen industrial parks (IPs) of the city, with various twists as textile, metalworking, chemical, bottling, food, pharmaceutical, etc.. Some industries and communities discharge their wastewater directly with little or no treatment into receiving bodies including Atoyac, Alseseca canyons and some rivers. The technological and industrial advances generated from the second half of the nineteenth century have resulted in multiple benefits for, suitable to personal needs humans.

Key words: Industrial parks, no running water, ravines, water quality.

Fecha recepción: Diciembre 2012

Fecha aceptación: Abril 2013

\section{Introducción}

México actualmente cuenta con una población aproximada de 112336538 millones de habitantes de los cuales 5779829 millones se ubican en la ciudad de Puebla, (INEGI, 2010). El gran incremento poblacional a nivel nacional y mundial está demandando altos volúmenes de agua para el consumo humano y otras actividades no menos importantes. Como consecuencia se están generando grandes cantidades de aguas residuales que constituyen focos de infección y toxicidad para la salud humana, así como para el ambiente. La ciudad de Puebla, México, capital del estado con el mismo nombre a través la Secretaría de Sustentabilidad y Ordenamiento Territorial informó que sólo 35 de las 278 plantas de tratamiento de aguas residuales que se encuentran en el estado de Puebla funcionan y están dentro de la norma, debido a que es caro para los municipios que las tienen a su cargo ponerlas en operación, (Camacho, 2013). Sin embargo el problema de la alta contaminación de los ríos se complica todavía más cuando las cinco plantas tratadoras de aguas residuales del Sistema 
Operador de Agua Potable y Alcantarillado de Puebla (SOAPAP) que existen en la capital poblana del estado solamente funcionaban al 60 por ciento de su capacidad, hasta el 2012.

No obstante es evidente que la contaminación de estos ríos la siguen generando también las industrias que arrojan sus aguas residuales no tratadas a las barrancas y que finalmente llegan a tan importantes recursos hídricos. El uso principal del agua de los ríos Atoyac y Alseseca es para el riego agrícola de las zonas de Atlixco e Izúcar de Matamoros y la mayor parte de ella se almacena en la presa Manuel Ávila Camacho para abastecer al Distrito de Riego 030 "Valsequillo", que beneficia a diecisiete municipios de la zona de Tacamachalco-Tehuacán.

La Norma Oficial Mexicana que se refiere a la reutilización de estos efluentes es la NOM-003-SEMARNAT-1997, (DOF, 2003), que establece los límites máximos permisibles de contaminantes para las aguas residuales tratadas que se reúsen en servicios al público. Debido a que las PTAR del estado de Puebla sólo alcanzan a tratar las aguas residuales en un 50 \% también se utilizará la NOM-001-SEMARNAT-1996, (DOF, 2003), que establece los límites máximos permisibles de contaminantes en las descargas de aguas residuales en aguas y bienes nacionales. Es evidente que las Normas Oficiales Mexicanas antes mencionadas no regulan parámetros agronómicos de calidad, como son el contenido de sales solubles, el contenido de sodio en relación con otros cationes y el contenido de elementos tóxicos para las plantas, y como estos son ampliamente utilizados y recomendados para el estudio de la calidad de aguas para riego agrícola tanto en México como en otras partes del mundo (Villanueva y Hernández, 2001; Steves et al., 2003; Cueto et al., 2005; Rodriguez-Ortiz et al., 2009), se llevará a cabo la determinación de estos parámetros de acuerdo a las Normas Mexicanas NMX-AA en materia de agua.

Las aguas residuales con altas concentraciones de sales disueltas deben de tener un manejo especial para ser utilizadas en el riego agrícola, debido a que se corre el riesgo de aumentar su concentración en el suelo, lo que provocaría una reducción en el 
potencial osmótico de la solución del suelo, que se traduce en una reducción del potencial total de agua en el suelo y como consecuencia provoca una disminución de su disponibilidad para el cultivo y el rendimiento del mismo (Castellanos et al., 2000). Cuando el sodio se encuentra en el agua en cantidades elevadas en relación con otros cationes, pude ocurrir que comience a ser adsorbido en grandes cantidades en el complejo de intercambio catiónico del suelo, aumentando el porcentaje de sodio intercambiable con respecto a otros cationes. Este proceso origina la formación de un suelo sódico que representa una serie de problemas para los cultivos agrícolas, debido a que provoca una dispersión coloidal que se traduce en una disminución drástica de la permeabilidad del suelo, además se generan condiciones adversas para el desarrollo de los cultivos al presentarse condiciones de inundación y anaerobiosis (Ortiz, 2000; Rodríguez-Ortiz et al., 2009). Entre los elementos tóxicos que más se mencionan por su efecto tóxico en las plantas aún en pequeñas cantidades se encuentran: el cloro, boro y sodio. Los dos primeros son elementos esenciales en los vegetales, pero en concentraciones apenas superiores a las indispensables empiezan a ser tóxicos para algunos cultivos (Mass, 1884; Rodríguez-Ortiz et al., 2009.

Glynn, 1999, menciona que los procesos convencionales de tratamiento de aguas residuales no incluyen la eliminación directa de todas las sustancias anteriormente mencionadas, ya que sólo se eliminan por tratamientos avanzados. Debido a esto se supone que existe una alta posibilidad de que aún permanezcan en las aguas después de pasar por las PTAR, en caso de haber estado presentes antes de su proceso. Por lo anteriormente mencionado es importante su determinación y clasificación en los efluentes para así proponer un uso adecuado y manejo de este recurso para que se logre una productividad sostenible y el aprovechamiento racional de los recursos naturales. Por su parte el gobierno federal pretende cubrir esta demanda a nivel nacional en un 60 \% para el año 2012, teniendo como objetivo alcanzar un manejo integral y sustentable del agua (Rodríguez-Ortiz et al., 2009). Por otro lado dentro del Plan Nacional de Desarrollo como estrategia se pretende propiciar un uso eficiente del agua en las actividades agrícolas, de tal forma que se reduzca el consumo inadecuado del líquido al tiempo que protegerán los suelos de la salinización (PND, 2007). 
Por lo anteriormente expuesto tomando en cuenta la gran contaminación prevaleciente en los ríos Atoyac y Alseseca que continua afectando en gran medida a los suelos agrícolas, cultivos, animales y pobladores de la ciudad de Puebla, del Distrito de Riego 030 "Valsequillo", así como también de la zona de riego de Atlixco e Izúcar de Matamoros, con riego restringido por esta contaminación, se realizó el presente estudio con el objetivo de determinar la calidad fisicoquímica y microbiológica de efluentes no entubados de barrancas ubicadas en dos parques industriales (PI), Puebla 2000 y 5 de mayo de la ciudad de Puebla. México, para difundir los resultados del monitoreo de la calidad del agua y prevenir a la población contra los riesgos a la salud y de esta manera contribuir a tomar decisiones para mejorar las condiciones de tan importantes recursos hídricos.

\section{Materiales y Métodos}

Fue una investigación prospectiva, descriptiva y observacional, el periodo de muestreo se realizó en la primera quincena del mes de mayo del 2011. La toma de las muestras de agua no entubada se organizó en dos etapas principales (de planeación y ejecución). Durante la etapa de planeación se delimitó el área de estudio, quedando conformada por secciones de los ríos ubicados al interior de tres barrancas que constituyen los límites físicos de dos parques industriales (PI) situados al norte del municipio de Puebla, el PI 5 de Mayo y el PI Puebla 2000, mostrados en la Figura 1; el primero rodeado en su frontera Noreste por la barranca de Guadalupe y en la Sureste por una sección de la barranca Del Conde, como se observa en la Figura 2, el segundo delimitado en su frontera Este por una sección de la barranca de San Antonio o Manzanilla expuesto en la Figura 3, todas formadas y abastecidas por escurrimientos del volcán extinto la Malintzin. 


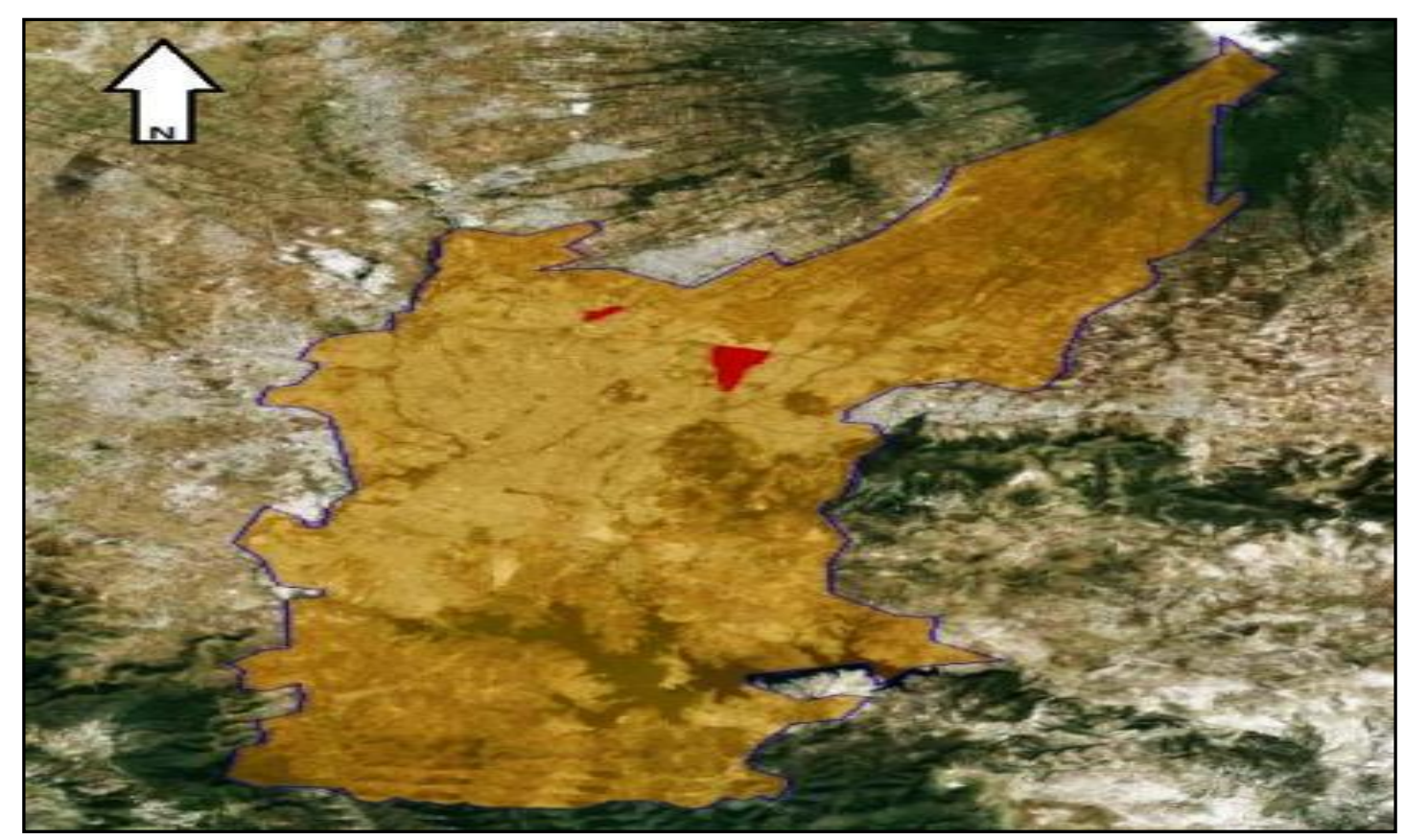

Figura 1. El municipio de Puebla (amarillo), parques industriales (rojos) 5 de Mayo ubicado al Norte, Puebla 2000 al Sur.

Fuente: Elaboración propia con base en INEGI/CONCYTEQ, 2010.

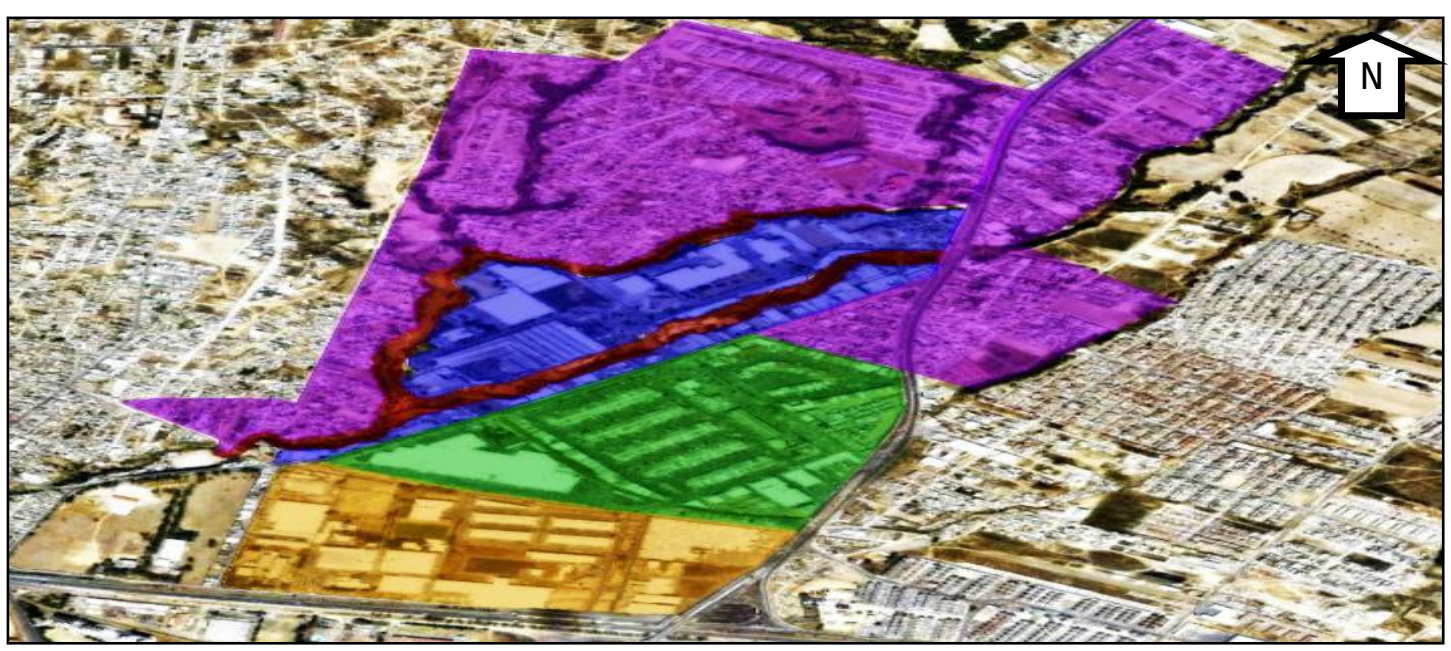

FIGURA 2. Parque Industrial 5 de Mayo (azul), secciones de barrancas (rojo) Guadalupe al Norte y el Conde al Sur, colonias cercanas (morado), central de abastos de la ciudad de Puebla (verde) y Fraccionamiento Industrial el Conde (naranja).

Fuente: Elaboración propia con base en trabajo de campo, 2011. 


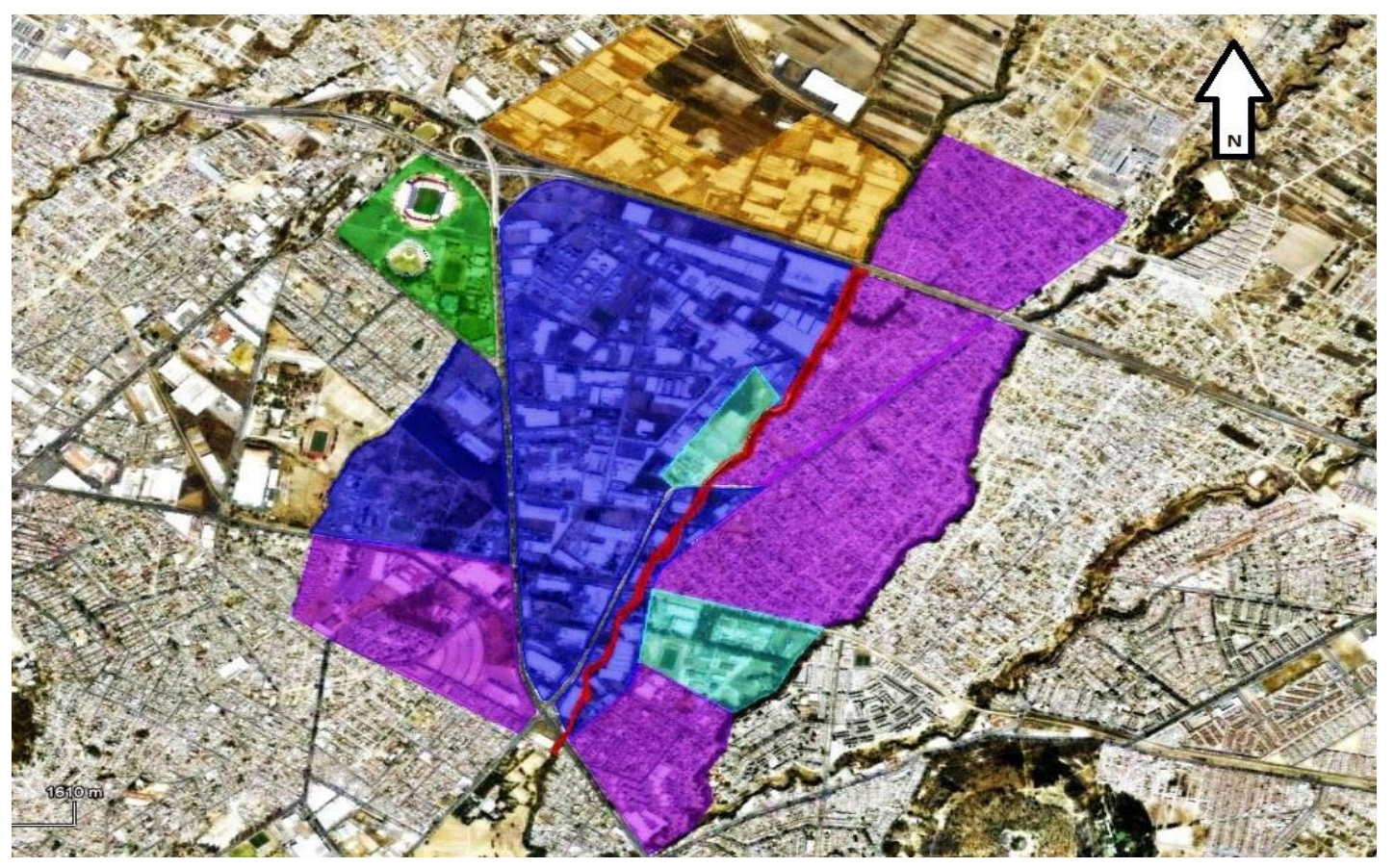

Figura 1. Parque industrial Puebla 2000 e industrias cercanas (azul), sección de barranca San Antonio (rojo), colonias cercanas (morado), Estadios Cuauhtémoc y Hermanos Serdán (verde), Parque Industrial Resurrección (naranja).

Fuente: Elaboración propia con base en trabajo de campo, 2011.

Una vez seleccionada el área de estudio se realizaron visitas a las autoridades en materia de agua de los niveles de gobierno federal y municipal, Comisión Nacional del Agua (CNA) y el Sistema Operador de Agua Potable y Alcantarillado de Puebla (SOAPAP) respectivamente. A fin de solicitar información de competencia exclusiva para cada nivel, de esta manera en la CNA se gestionó el acceso a la base de datos con las descargas y permisos de uso de agua para fines industriales de las empresas instaladas en los parques industriales de interés, así como planos que detallaran el sistema de ríos que cruzan la ciudad de Puebla a fin de establecer el posible caudal de descarga y la trayectoria de los contaminantes, dicha información se solicitó a través del Instituto Federal de Acceso a la Información y mediante oficio Institucional, en ambos casos la respuesta fue negativa.

Únicamente las autoridades de SOAPAP, brindaron todas las facilidades para acceder a entrevistas con funcionarios de la misma dependencia, consulta de reportes públicos y 
una copia impresa del sistema de alcantarillado actualizado al 2009 del municipio de Puebla, donde previamente se habían solicitado planos o diagramas de los sistemas recolectores de agua residual en la ciudad de Puebla y de manera particular de aquellos ubicados cerca del área de estudio, así como del volumen de descarga estimado a las barrancas, ya que en visitas a los parques industriales se observaron salidas de drenaje de las industrias y de las casas habitación asentadas en los márgenes de las tres barrancas. De esta manera, se comprobó que si bien los parques industriales se encuentran conectados a la red de drenaje y alcantarillado municipal, una fracción de las industrias aun realizan descargas fuera de la red; sin embargo, en el caso de las la zona habitacional en las colonias circundantes al PI 5 de Mayo no es el mismo, ya que algunas (caso PI 5 de Mayo) al ser "nuevas" no cuentan aún con los servicios públicos completos como alumbrado público, recolección regular de basura y drenaje público, mientras que otras (caso PI Puebla 2000) que ya cuentan con los servicios anteriores, mantienen un drenaje de agua residual hacia las barrancas.

La red de muestreo se observa en las Figuras 4 y 5, se estableció utilizando imágenes satelitales e información recolectada en vistas a la zona, en donde se registraron coordenadas geográficas, así como los caminos de acceso a las barrancas eligiéndose diez estaciones para la toma de muestras, distribuidas en las barrancas de Guadalupe, Del Conde y San Antonio. Para la elección de las mismas se buscó que representaran lo mejor posible las características del efluente total, para lo cual se utilizaron tres criterios principales: la accesibilidad a los sitios, la existencia de drenajes (industrial y sanitario) hacia las barrancas y la disposición de sitios en la parte superior, media e inferior del cauce.

Las diez estaciones de muestreo se observan en las Figuras 4 y 5, se establecieron utilizando imágenes satelitales e información recolectada en vistas a la zona de estudio, en donde se registraron las coordenadas geográficas, así como los caminos de acceso a las barrancas eligiéndose elegidas, estas se encuentran distribuidas en las barrancas de Guadalupe, Del Conde y San Antonio. Para la elección de las mismas se buscó que representaran lo mejor posible las características del efluente total, para lo cual se utilizaron tres criterios principales: la accesibilidad a los sitios, la existencia de 
drenajes (industrial y sanitario) hacia las barrancas y la disposición de sitios en la parte superior, media e inferior del cauce.

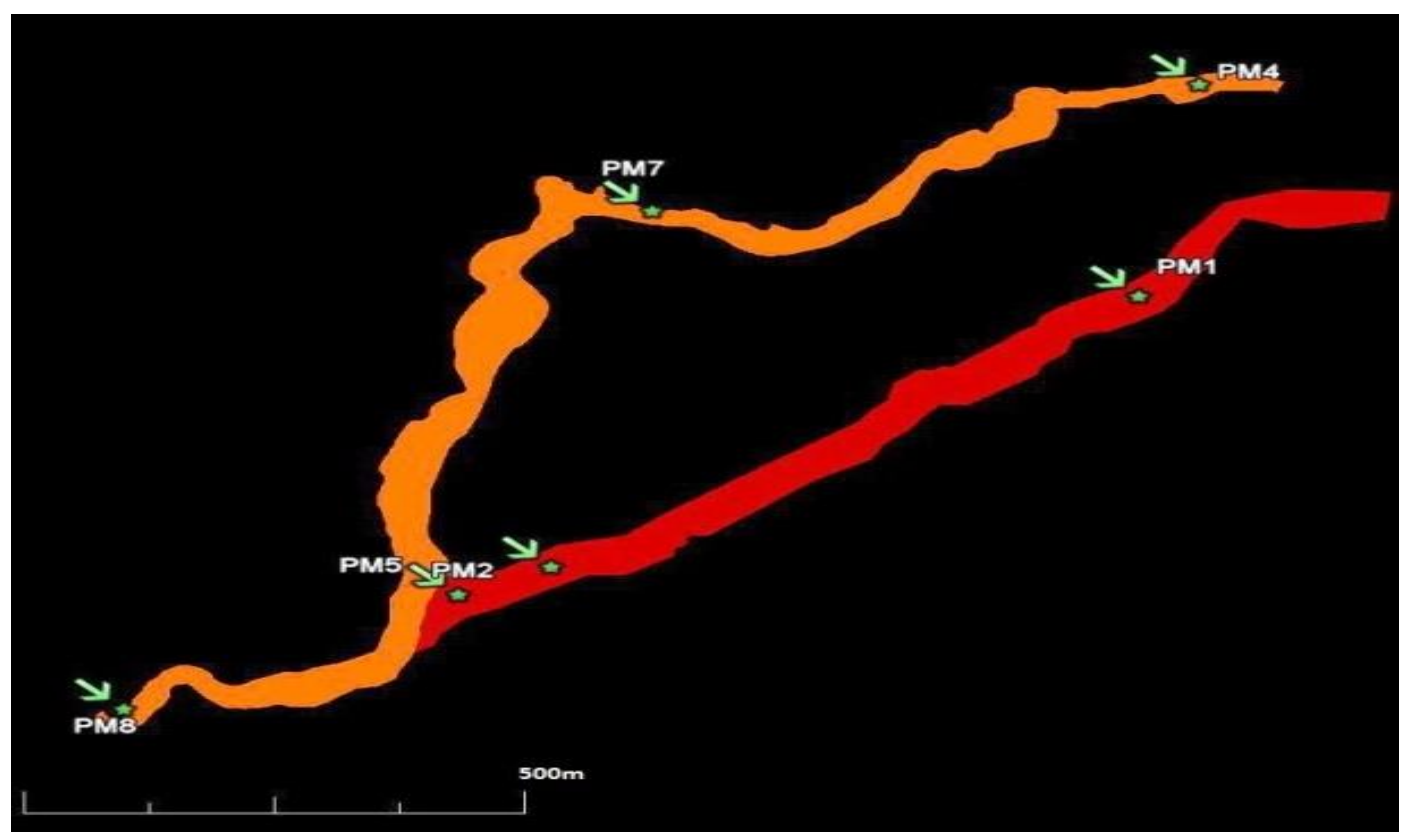

Figura 4. Red de muestreo PI 5 de Mayo.

Fuente: Elaboración propia con base en trabajo de campo, 2011.

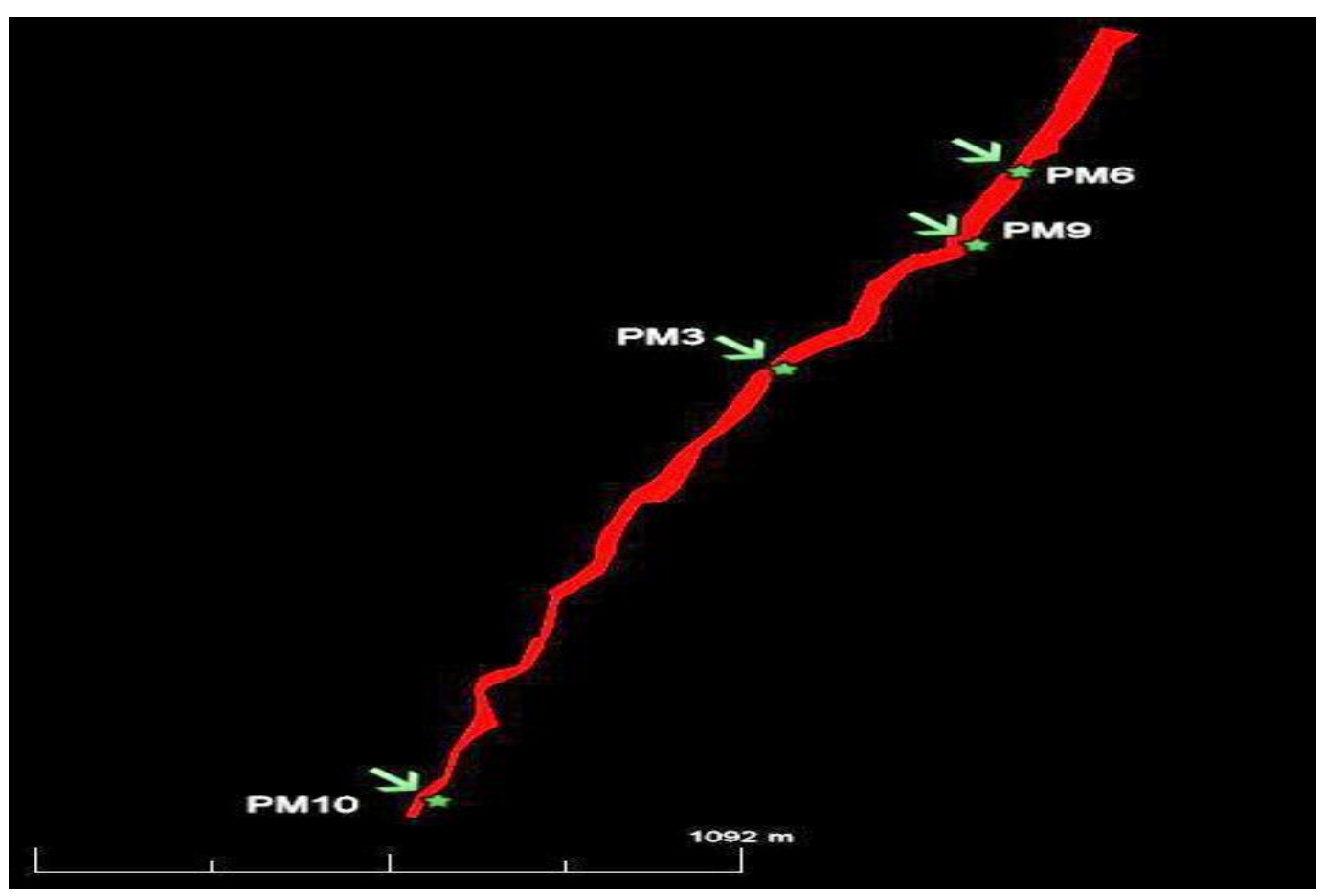




\section{Figura 5. Red de muestreo PI Puebla 2000.}

Fuente: Elaboración propia con base en trabajo de campo, 2011.

Durante la etapa de ejecución se realizó la toma de muestras, se desarrolló durante el cambio entre la época de estiaje y la de precipitación pluvial. Se consideró la metodología propuesta por la norma técnica NMX-AA-014-1980, (DOF, 1980). Se midió el caudal de la corriente utilizando el método del flotador, registrando su promedio con base a tres repeticiones.

Se tomaron un total de diez muestras de agua residual no entubada de los dos parques industriales (PI) de la ciudad de Puebla, México, que difieren entre sí por los diferentes procesos industriales y por su origen, la toma de las muestras se realizó los días 11, 13 y 16 de mayo del 2012. Se utilizaron recipientes de polipropileno nuevos lavados con solución de ácido nítrico $1 \mathrm{~N}$, enjuagados con agua desionizada varias veces y al momento de la toma de la muestra de agua se enjuagaron en tres ocasiones con la misma agua a analizar, para los análisis de coliformes fecales las muestras se tomaron en frascos estériles. Las muestras fueron colocadas en hieleras y trasladadas lo más pronto posible al laboratorio para su análisis. Los análisis físicos, químicos y bacteriológicos se determinaron conforme a las Normas Mexicanas en materia de agua.

Los indicadores que se midieron de los efluentes para poder determinar la calidad agronómica del agua siguiendo la secuencia reportada por (Rodríguez-Ortíz et al., 2009), adicionando otros indicadores para realizar la comparación de los límites máximos permisibles de las Normas Oficiales Mexicanas utilizadas en este trabajo.

Para la evaluación del peligro por presencia de sales se determinaron los siguientes indicadores: Conductividad Eléctrica (CE) que se usa como una medida indirecta del contenido de sales. Se determinó con un conductímetro portátil CONDUCTRONIC en campo, en el laboratorio se reprodujeron las condiciones de temperatura tomada en campo para su comprobación con un conductímetro de mesa CONDUCTRONIC; Salinidad Efectiva (SE), que representa una estimación más real del peligro que 
presentan las sales solubles del agua de riego al pasar a formar parte de la solución del suelo, debido a que se toma en cuenta la precipitación posterior de las sales menos solubles (carbonatos de calcio y magnesio, además de sulfato de calcio), los que por posteriormente dejan de participar en la elevación de la presión osmótica de la solución del suelo; Salinidad Potencial (SP), con la cual se estima el peligro de las sales de cloro y sulfatos que pueden persistir como iones solubles al disminuir la humedad del suelo por debajo del $50 \%$, se calculó con la fórmula $\mathrm{SP}=\mathrm{Cl}+0.5 \cdot \mathrm{SO}_{4}{ }^{2-}$.

Los indicadores de peligro de sodio que se determinaron son: relación de adsorción de sodio (RAS), que es uno de los índices más difundido para medir el peligro de sodificación que presenta el agua de riego; se calculó con la formula: RAS= $\mathrm{Na} \cdot\left[(\mathrm{Ca}+\mathrm{Mg})^{-2}\right]^{1 / 2}$; carbonato de sodio residual (CSR), que estima el riesgo de que se formen carbonatos de sodio después de la precipitación de carbonatos de calcio y magnesio. Se calculó con la fórmula $\mathrm{CSR}=\left(\mathrm{CO} 3+\mathrm{HCO}^{-}\right)-\left(\mathrm{Ca}^{2+}+\mathrm{Mg}^{2+}\right)$. También se obtuvo el porciento de sodio posible PSP, que se refiere al peligro del desplazamiento del calcio y del magnesio por el sodio, en el complejo de intercambio, empieza cuando el contenido de sodio en la solución representa más de la mitad de los cationes disueltos. Reducción de la infiltración. Se obtiene de los valores conjuntos de RAS y CE, con ellos se usa la clasificación de la FAO que ofrece tres categorías en la restricción del uso del agua: ninguna, leve o moderada y severa.

Los cationes y aniones fueron determinados de acuerdo a las siguientes metodologías: calcio y magnesio por valoración complejométrica con EDTA; sodio y potasio, por flamometría (flamómetro Corning 400), carbonatos y bicarbonatos por volumetría ácido-base, cloruros por volumetría de precipitación (método de Mohr), sulfatos por espectrofotométria utilizando el método turbidimétrico.

Como ion tóxico se evaluó el ion cloruro y sodio. Los otros indicadores que se evaluaron fueron: temperatura $\left(\mathrm{T}^{\circ} \mathrm{C}\right), \mathrm{pH}$ (potenciométrico), materia flotante (físico), sólidos sedimentables (SSe), sólidos suspendidos totales (SST), sólidos disueltos totales (SDT). Para la clasificación de cada uno de los parámetros se tomaron las metodologías de de Palacios y Aceves (1970), del Departamento de Agricultura de los Estados Unidos 
de Norteamérica (USDA, Laboratorio de Riverside). También fueron consideradas las metodologías de Ayres y Westcot (1976) y Suárez (1981).

Las muestras de agua se tomaron directamente de las corrientes de las descargas, se recolectaron en recipientes limpios y secos de polipropileno con capacidad de 10.0 litros para análisis fisicoquímicos, en envases de vidrio para grasas y aceites y para los análisis microbiológicos (coliformes fecales) se usaron recipientes de polipropileno estéril, con tapa hermética en forma de rosca de $120 \mathrm{~mL}$ de capacidad, tomando la muestra directamente del cauce. Para la realización de los análisis en laboratorio las muestras de agua se preservaron conforme a la norma NMX-AA-003-1980 y el manual de la Eaton, 2005. Y para los análisis bacteriológicos se procesaron, según los procedimientos descritos en el PROY-NMX-AA-042/1-SCFI-2008. Análisis de agua Detección y enumeración de organismos coliformes, organismos coliformes termotolerantes y Escherichia coli presuntiva. (Secretaría de Economía, 2005).

En el Cuadro 1 se muestran: la ubicación, coordenadas geográficas, altura y nombre del parque industrial de las diez estaciones de muestreo de agua residual.

\begin{tabular}{|c|c|c|c|c|c|}
\hline \multicolumn{6}{|c|}{ Cuadro 1. Ubicación de las estaciones de muestreo } \\
\hline & \multirow{2}{*}{ Ubicación } & \multicolumn{2}{|c|}{ Coordenadas geográficas } & \multirow{2}{*}{$\begin{array}{l}\text { Altura } \\
\text { msnm }\end{array}$} & \multirow{2}{*}{$\begin{array}{l}\text { Parque } \\
\text { industrial }\end{array}$} \\
\hline & & Norte & Oeste & & \\
\hline 1 & Barranca del Conde I & $\begin{array}{l}19^{\circ} 05^{\prime} 47.70 \\
\prime\end{array}$ & $\begin{array}{l}98^{\circ} 11^{\prime} 10.28 \\
\prime \prime\end{array}$ & 2225 & 5 de mayo \\
\hline 2 & Barranca del Conde II & $\begin{array}{l}19^{\circ} 05^{\prime} 35.83 \\
\prime \prime\end{array}$ & $98^{\circ} 11^{\prime} 30.50$ & 2200 & 5 de mayo \\
\hline 3 & Barranca de San Antonio & $\begin{array}{l}19^{\circ} 03^{\prime} 57.90 \\
\prime \prime\end{array}$ & $\begin{array}{l}98^{\circ} 09^{\prime} 09.50 \\
"\end{array}$ & 2227 & Puebla 2000 \\
\hline 4 & Barranca de Guadalupe & $\begin{array}{l}19^{\circ} 05^{\prime} 58.70 \\
\end{array}$ & $\begin{array}{l}98^{\circ} \\
11^{\prime} 08.20^{\prime \prime}\end{array}$ & 2225 & 5 de mayo \\
\hline 5 & Barranca del Conde III & $\begin{array}{l}19^{\circ} 05^{\prime} 32.40 \\
\prime\end{array}$ & $\begin{array}{l}98^{\circ} \\
11^{\prime} 33.70^{\prime \prime}\end{array}$ & 2193 & 5 de mayo \\
\hline
\end{tabular}




\begin{tabular}{|c|c|c|c|c|c|}
\hline 6 & Barranca de San Antonio I & $\begin{array}{l}19^{\circ} 04^{\prime} 18.10 \\
\prime \prime\end{array}$ & $\begin{array}{l}98^{\circ} \\
08^{\prime} 57.00^{\prime \prime}\end{array}$ & 2238 & Puebla 2000 \\
\hline 7 & Barranca de Guadalupe & $19^{\circ} 05^{\prime} 52.18$ & $98^{\circ} 11^{\prime} 27.02$ & 2247 & 5 de mayo \\
\hline 8 & $\begin{array}{l}\text { Barranca del Conde (Avenida } \\
\text { gasoducto) }\end{array}$ & $19^{\circ} 05^{\prime} 26.50$ & $\begin{array}{l}98^{\circ} \\
11^{\prime} 45.20^{\prime \prime}\end{array}$ & 2192 & 5 de mayo \\
\hline 9 & $\begin{array}{l}\text { Barranca de San Antonio II } \\
\text { (atrás de Sony Gas) }\end{array}$ & $\begin{array}{l}19^{\circ} 04^{\prime} 10.60 \\
\prime \prime\end{array}$ & $\begin{array}{l}98^{\circ} \\
08^{\prime} 59.30^{\prime \prime}\end{array}$ & 2219 & Puebla 2000 \\
\hline 1 & $\begin{array}{l}\text { Barranca de San Antonio III } \\
\text { (puente antigua Pepsi) }\end{array}$ & $\begin{array}{l}19^{\circ} 03^{\prime} 13.70 \\
" N\end{array}$ & $\begin{array}{l}98^{\circ} \\
09^{\prime} 27.80^{\prime \prime}\end{array}$ & 2193 & Puebla 2000 \\
\hline
\end{tabular}

\section{Resultados y Discusión}

\section{Indicadores del peligro de sales}

En el Cuadro 2. Se muestran los resultados de los parámetros considerados como indicadores del peligro de sales solubles.

Respecto a la conductividad eléctrica, se encontró que las estaciones 4, 6, 7, 9 y 10 son aguas altamente salinas, correspondiendo el valor mínimo a la estación 7 (PI 5 de mayo) de 0,87 d S $\mathrm{S}^{\mathrm{m}-1}$, y el valor máximo a la estación 5 de mismo (PI) de $4.16 \mathrm{~d} \mathrm{~S}^{\mathrm{m}-1}$, con un promedio de $2.32 \mathrm{~d} \mathrm{~S}^{\mathrm{m}-1}$ quedando clasificadas las otras nueve estaciones como agua muy altamente salina.

En cuanto a la SE fue obtenido un valor mínimo de 3.06, un máximo de 17.37 y un promedio de 10.62 todos en meq $\mathrm{L}^{-1}$, siendo las estaciones $1,2.4,5,6,7,8 \mathrm{y}$ el promedio las que quedaron clasificadas como agua condicionada y las estaciones 3, 9, y 10 se clasificaron como agua no recomendable.

Para la SP se obtuvieron valores que variaron de 1.63 a $11.87 \mathrm{meq} \mathrm{L}^{-1}$ con valor medio de 5.42 meq $\mathrm{L}^{-1}$, quedando clasificadas como buenas las estaciones $4,6,7$ y 8 y como condicionadas la estación 1, 2, 3, 5, 9 y 10 y el promedio como condicionadas. 
Los indicadores de peligro de sales mostraron que el uso para riego agrícola de la mayoría de las aguas residuales no entubadas provenientes de los PI 5 de mayo y Puebla 2000 no son recomendable en su mayoría y de ser empleadas debe hacerse bajo un manejo cuidadoso de tipo preventivo para no salinizar a los suelos agrícolas que sean regados o para no incrementar el contenido de sales. El aumento de la salinidad en los suelos provoca la reducción de la producción de los cultivos.

El problema de sales se restringe a regiones con precipitación pluvial limitada (como es el caso del Distrito de Riego 030 "Valsequillo" en donde se utiliza el agua almacenada de la presa Manuel Ávila Camacho conocida como Valsequillo, en donde las Iluvias son muy escasas y no son de suficiente magnitud como para desplazar las sales de los perfiles de los suelos), Castellanos et al., 2000 mencionan que normalmente en regiones con más de $600 \mathrm{~mm}$ de lluvia el riesgo de salinización no es alto si el agua de riego no es de tan mala calidad. Se estima que la superficie afectada por sales en México es del orden de un millón de ha, México es del orden de un millón (Fernández, 1990) 


\begin{tabular}{|c|c|c|c|}
\hline \multicolumn{4}{|c|}{$\begin{array}{l}\text { Cuadro 2. Clasificación del agua no entubada de los PI } 5 \text { de Mayo y Puebla } 2000 \\
\text { respecto al contenido de sales solubles }\end{array}$} \\
\hline$E$ & CE dS $\mathrm{m}^{-1}$ & SE meq L & SP meq L \\
\hline 1 & 3.26 & $10.53^{c}$ & $5.81^{\mathrm{C}}$ \\
\hline 2 & 2.96 & $9.83^{c}$ & $6.84^{c}$ \\
\hline 3 & 2.72 & $17.37 *$ & $5.06^{c}$ \\
\hline 4 & $1.26 *$ & $5.76^{c}$ & $1.63^{B}$ \\
\hline 5 & 4.16 & $14.73^{c}$ & $11.87^{c}$ \\
\hline 6 & $1.31^{*}$ & $5.28^{c}$ & $2.47^{B}$ \\
\hline 7 & $876 *$ & $3.06^{c}$ & $2.85^{B}$ \\
\hline 8 & 2.92 & $8.48^{c}$ & $2.95^{B}$ \\
\hline 9 & $1.98 *$ & $15.90 *$ & $8.06^{c}$ \\
\hline 10 & $1.74^{*}$ & $15.24 *$ & $6.68^{c}$ \\
\hline PROM. & 2.32 & $10.62^{c}$ & $5.42^{c}$ \\
\hline Min & 876 & 3.06 & 1.63 \\
\hline Max & 4.16 & 17.37 & 11.87 \\
\hline CLASF. & $\begin{array}{l}\text { *Agua salina } \\
* * \text { Agua altamente } \\
\text { salina }\end{array}$ & $\begin{array}{l}\text { C Condicionada } \\
{ }^{*} \text { NR } \\
\text { Recomendable }\end{array}$ & $\begin{array}{l}\text { B Buena } \\
\text { CCondicionada }\end{array}$ \\
\hline
\end{tabular}


Es importante tomar en cuenta todos los posibles factores que intervienen en el proceso de producción de los cultivos para un adecuado manejo de aguas condicionadas, entre ellos: el cultivo, el suelo, método de riego, clima, drenaje interno, etc. Entre los tratamientos para prevenir la salinidad en los suelos al regar con estas aguas incluye opciones como la desalinización por destilación y la ósmosis inversa o la desionización mediante el uso de diferentes resinas intercambiadoras (Ortiz, 2000 y Rodríguez-Ortíz et al., 2009). Sin embargo los mismos autores mencionan que estos procesos requieren de un gasto energético muy costoso para llevarse a cabo a gran escala. Otra opción es el lavado de suelos, donde las sales se desplazan en el perfil del suelo donde se encuentran las raíces del cultivo de manera que estas sean igual a la aportada poe el agua de riego. Rodríguez-Ortiz et al., 2009) mencionan que Rhoades y Merrill, (1976) establecieron la ecuación para calcular el requerimiento del lavado:

$$
L R=\frac{E C_{w}}{5(E C e)-E C_{w}}
$$

Donde:

$\mathrm{LR}=$ Requerimiento mínimo de lixiviación para control de sales con métodos de riego por gravedad

$E C_{W}=$ Salinidad del agua aplicada $\left(\mathrm{dS} \mathrm{m}^{-1}\right)$

$\mathrm{ECe}=$ Salinidad media del suelo tolerada por el cultivo $\left(\mathrm{dS} \mathrm{m}^{-1}\right)$

El lavado es la medida de mejoramiento más eficaz para combatir la salinización primaria, así como para prevenir la salinización secundaria, Flores et al., (1996). El lavado de los suelos sin el uso de mejoradores favorece la penetración del sodio al complejo adsorbente, debido al aumento relativo de la actividad del sodio en solución respecto al calcio y por esto es la necesidad de ampliar la utilización de los mismos en todos los suelos salinos como medida preventiva a la sodificación como explica Otero, (1993) y RodríguezOrtiz et al., 2009), Por otro lado Aceves, (1987), menciona que el uso de mejoradores se 
basa en la aplicación de sustancias que contienen calcio para que promuevan su aumento en la solución del suelo y se intercambie con el sodio adsorbido para que después sea removido por el lavado. De esta forma el suelo se mantiene floculado y el pH se neutraliza.

En caso de ser necesario, se podrá recurrir al establecimiento de cultivos que toleren la salinidad existente. Esta opción es un tanto complicada en el sentido de que no siempre un cultivo tolerante o semitolerante puede sustituir parcial o totalmente a los cultivos de importancia económica de la zona por razones de mercado.

Una de las medidas que se proponen y que son citadas por Rodríguez-Ortiz et al., 2009, es implementar un sistema de cultivos de descanso y rotación con el uso de abonos verdes, de esta manera se evita por un tiempo la incorporación de sales al suelo por el riego de aguas salinas, a la vez se beneficia un poco el arrastre de estas por las lluvias ayudándose con la materia orgánica que induce la formación de agregados los cuales mejoran la estructura del suelo y se obtiene un mejor movimiento de las sales en el perfil del suelo (Martínez et al., 1986; Miller y Cifres, 1988; Otero et al., 1993).

\section{Indicadores del peligro de sodio}

Las concentraciones de los indicadores de peligro de sodio que fueron considerados para la realización de este trabajo fueron: la relación de adsorción de sodio RAS, el carbonato de sodio residual CSR y el porciento de sodio posible PSP mostrados en el Cuadro 3.

La relación de adsorción de sodio RAS presentó valores de 1.71 a 8.67 meq $\mathrm{L}^{-1}$ con un valor medio de 4.64 meq $\mathrm{L}^{-1}$ de acuerdo a la clasificación de Palacios Aceves (1994) que relaciona la RAS con la conductividad eléctrica, la aguas no entubadas se clasificaron de la 
siguiente manera: para las estaciones 4, 6 y 7 como C3-S1, C3: agua altamente salina que no debe usarse en suelos cuyo drenaje sea deficiente, debiendo, por tanto, seleccionarse únicamente aquellas especies vegetales muy tolerantes a las sales y S1: agua baja en sodio, puede usarse para el riego en la mayoría de los suelos con poca probabilidad de alcanzar niveles peligrosos de sodio intercambiable. Las estaciones 9 y 10 quedaron clasificadas como C3-S2, en donde S2: agua media en sodio, la cual en suelos de textura fina el sodio representa un peligro considerable más aún si el suelo poseen una alta CIC, especialmente bajo condiciones de lavado deficiente, a menos que el suelo contenga yeso. Solo deben usarse en suelos de textura gruesa o en suelos orgánicos de buena permeabilidad. Las estaciones 1, 2, 5 y 8 se clasificaron como C4-S2 en donde C4: corresponde a agua muy altamente salina, no apropiada para riego bajo condiciones ordinarias, pudiéndose usar ocasionalmente en circunstancias muy especiales. Los suelos deben ser permeables, el drenaje adecuado, debiendo aplicarse un exceso de agua para lograr un buen lavado. En este caso se deben seleccionar cultivos altamente tolerantes a sales; por último la estación la estación 3 quedo clasificada como C4-S3 en donde S3: agua alta en sodio, puede producir niveles tóxicos de sodio intercambiable en la mayor parte de los suelos, necesitándose prácticas especiales de manejo, buen drenaje, fácil lavado y adiciones de materia orgánica. Los suelos yesíferos pueden no desarrollar niveles perjudiciales de sodio intercambiable cuando se riega con este tipo de aguas. Puede requerirse el uso de mejoradores químicos para sustituir al sodio intercambiable; sin embargo, tales mejoradores no son económicos si se usan aguas de muy alta salinidad.

\begin{tabular}{|l|l|l|l|l|l|}
\hline \multicolumn{2}{|l|}{} & \multicolumn{2}{l}{$\begin{array}{l}\text { Cuadro 3. Clasificación del agua respecto al efecto probable del Na sobre las } \\
\text { características físicas del suelo }\end{array}$} \\
\hline E & *RAS & *CE & $* *$ CSR & PSP & $\begin{array}{l}\text { Clasificación } \\
\text { CE y RAS }\end{array}$ \\
\hline
\end{tabular}




\begin{tabular}{|l|l|l|l|l|l|}
\hline & $\mathrm{meq} \mathrm{L}^{-1}$ & $\mu \mathrm{Cm}^{-1}$ & $\mathrm{meq} \mathrm{L}^{-1}$ & $\mathrm{meq} \mathrm{L}^{-1}$ & \\
\hline 1 & $5.03^{\mathrm{B}}$ & 3260 & $2.22^{\mathrm{C}}$ & 91.79 & (C4-S2) \\
\hline 2 & $3.81^{\mathrm{B}}$ & 2960 & $0.00^{\mathrm{B}}$ & 88.49 & (C4-S2) \\
\hline 3 & $8.67^{\mathrm{B}}$ & 2720 & $8.79^{\mathrm{NR}}$ & 94.79 & (C4-S2) \\
\hline 4 & $2.70^{\mathrm{B}}$ & 1265 & $2.71^{\mathrm{C}}$ & 87.03 & (C3-S1) \\
\hline 5 & $4.70^{\mathrm{B}}$ & 4160 & $0.00^{\mathrm{B}}$ & 91.59 & (C4-S2) \\
\hline 6 & $1.99^{\mathrm{B}}$ & 1309 & $0.96^{\mathrm{B}}$ & 78.22 & (C3-S1) \\
\hline 7 & $1.71^{\mathrm{B}}$ & 876 & $0.00^{\mathrm{B}}$ & 84.89 & (C3-S1) \\
\hline 8 & $3.59^{\mathrm{B}}$ & 2920 & $4.03^{\mathrm{NR}}$ & 89.69 & (C4-S2) \\
\hline 9 & $6.61^{\mathrm{B}}$ & 1985 & $4.62^{\mathrm{NR}}$ & 91.96 & (C3-S2) \\
\hline 10 & $7.55^{\mathrm{B}}$ & 1742 & $5.91^{\mathrm{NR}}$ & 91.99 & (C3-S2) \\
\hline PROM. & $4.64^{\mathrm{B}}$ & 2319.7 & $2.92^{\mathrm{NR}}$ & 89.04 & -- \\
\hline Min. & 1.71 & 876 & 0.00 & 78,22 & C3-S1 \\
\hline Max. & 8.67 & 4160 & 8.79 & 94.79 & C4-S2 \\
\hline CLAS. & -- & & -- & $\mathrm{C}$ & \\
\hline
\end{tabular}

*Metodología USDA, RAS: Baja (B) < 10; Media (M) 10-18; Alta (A)18-25; Muy Alta MA > 25

*Metodología USDA. CE: Bajo < 250; Medio 250-750; Alto 750-2250; Muy alto > 2250 en $\mu \mathrm{Scm}^{-1}$

** Metodología de Palacios y Aceves 1994. B= buena: $C=$ condicionada; $N R=$ no recomendable

Indicador Ion Tóxico $\mathrm{Cl}^{-}$

En cuanto a las concentraciones del ion cloruro cuyas valores se muestran en el Cuadro 4, se observa que variaron de 1.00 a $7.30 \mathrm{meq} \mathrm{L}^{-1}$, con un promedio de $3.38 \mathrm{meq} \mathrm{L}^{-1}$, excepto 
la estación 4 quedando en el límite de la clasificación como buena, las estaciones 1, 2, 3, 6, 7, 8 y 10 presentaron valores menores de 5.00 meq $\mathrm{L}^{-1}$ quedando clasificadas como condicionadas y las estaciones 5 y 9 se clasificaron como no recomendables.

Rodríguez-Ortíz et al., 2009 mencionan que el mejoramiento de las aguas residuales condicionadas a nivel de plantas de tratamiento puede realizarse por tratamiento terciario, también conocido como avanzado. Algunos tratamientos como ósmosis inversa, carbón activado, electrodiálisis y otros pudieran utilizarse para eliminar este tipo de sustancias sin embargo, aún no se implementa en todas las plantas de tratamiento, pero que un futuro será implementado según sea la necesidad del reúso del agua, (Ramalho, 1996).

\begin{tabular}{|l|l|l|l|}
\hline \multicolumn{2}{|l}{ Cuadro 4. Clasificación del agua respecto al contenido del ion Cl } \\
\hline & Cl $^{-}$ & $\begin{array}{l}\text { Clasificación } \\
\text { Eceves y Palacios, 1994 }\end{array}$ & $\begin{array}{l}\text { Metodología } \\
\text { de la FAO }\end{array}$ \\
\hline 1 & 3.64 & Condicionada & Ligera a moderada restricción \\
\hline 2 & 4.32 & Condicionada & Ligera a moderada restricción \\
\hline
\end{tabular}




\begin{tabular}{|l|l|l|l|}
\hline 3 & 3.16 & Condicionada & Ligera a moderada restricción \\
\hline 4 & 1.00 & Buena & Ninguna restricción \\
\hline 5 & 7.30 & No Recomendable & Ligera a moderada restricción \\
\hline 6 & 1.54 & Condicionada & Ninguna restricción \\
\hline 7 & 1.76 & Condicionada & Ninguna restricción \\
\hline 8 & 1.82 & Condicionada & Ninguna restricción \\
\hline 9 & 5.06 & No Recomendable & Ligera a moderada restricción \\
\hline 10 & 4.20 & Condicionada & Ligera a moderada restricción \\
\hline PROM & 3.38 & Condicionada & Ligera a moderada restricción \\
\hline Min & 1.00 & ---- & ---- \\
\hline Max & 7.3 & ---- & - \\
\hline
\end{tabular}

Ayers y Wescot (1985) citados por Rodríguez-Ortíz et al., 2009 mencionan que hay que tener cuidado cuando se rieguen cultivos por aspersión, debido a que el $\mathrm{Cl}^{-}$también puede ser absorbido por las partes aéreas de la planta. Esta situación representa un problema para los efluentes de las aguas tratadas no entubadas que son arrojadas a los ríos y que posteriormente serán utilizadas para el riego de cultivos, ya que los valores de cloruros variaron entre 1.00 y $7.30 \mathrm{me} \mathrm{L}^{-1}$. Sin embargo, habrá que cuidar la acción conjunta de las aguas y el suelo ya que Mengel y Kirkby (1982) mencionan que los cultivos que crecen en suelos afectados por sales frecuentemente muestran síntomas de toxicidad por $\mathrm{Cl}^{-}$, estos incluyen el quemado de las puntas o márgenes, bronceado y amarillamiento prematuro y separación de hojas. La reducción en rendimiento y calidad de los cultivos está asociada con niveles de $0.5 \%$ de $\mathrm{Cl}$ en tejido para cultivos sensitivos y $4 \%$ ó más en la materia seca de cultivos tolerantes.

Indicadores físicos y químicos 
Los parámetros fisicoquímicos determinados para realizar la clasificación de la calidad del agua se muestran en el Cuadro 5, en donde los resultados obtenidos se compararon con los límites máximos permisibles de las NOM-001-SEMARNAT-1996 y la NOM-003SEMARNAT-1997, (DOF, 2003).

Los valores de $\mathrm{pH}$ variaron de 5.7 a 7.7 con valor medio de 7.07 unidades de $\mathrm{pH}$, no rebasando ninguna de ellas el límite máximo permisible de la NOM-001, las estaciones 1, 2 y 6 presentaron pH menores a 7.0, la estación 9 mostró un $\mathrm{pH}=7$ (neutro) y las mayores a 7.0 fueron las estaciones $3,4.5 .7 .8$ y 10 valores clasificados como permisibles en la normatividad mexicana, en cuanto a la clasificación de la FAO, solamente la estación 6 quedo fuera del rango, que es de 6,5 8.4, presentando un valor ácido.

La conductividad eléctrica expresada en $\mu \mathrm{S} \mathrm{cm}^{-1} \mathrm{es}$ uno de los parámetros más importantes dentro de las determinaciones de la calidad de un agua para riego, puesto que nos da información de la concentración de las sales solubles. En esta investigación el valor mínimo obtenido fue de $876 \mu \mathrm{S} \mathrm{cm}^{-1}$ en la estación 7 el máximo fue de $4160 \mu \mathrm{S} \mathrm{cm}-1$ en la estación 5 encontrándose un promedio $2319.70 \mu \mathrm{S} \mathrm{cm}^{-1}$, las estaciones que presentaron valores menores a $200070 \mu \mathrm{S} \mathrm{cm}^{-1}$ fueron: de la más baja a la más alta la 7,4, 6, 10 y 9 y las mayores $2000 \mu \mathrm{S} \mathrm{cm}^{-1}$ correspondieron a las estaciones 3, 8, 2, 1 y 5 quedando estas últimas como condicionadas para riego de acuerdo con Palacios y Aceves (1994).

Cuadro 5. Resultados de los parámetros físicos de las diez estaciones de muestreo de agua
residual no entubada.
\begin{tabular}{|l|l|l|l|l|l|l|l|l|}
\hline E & $\begin{array}{l}\text { Caudal } \\
\mathrm{m}^{3} \mathrm{~s}^{-1}\end{array}$ & $\begin{array}{l}\text { Temp. } \\
{ }^{\circ} \mathrm{C}\end{array}$ & $\begin{array}{l}\text { Materia } \\
\text { flotante }\end{array}$ & $\begin{array}{l}\mathrm{pH} \\
\text { unidades }\end{array}$ & $\mu \mathrm{CS} \mathrm{cm}$ & $\mathrm{mg} \mathrm{L}^{-1}$ & $\mathrm{mg} \mathrm{L}^{-1}$ & $\mathrm{mg} \mathrm{L}^{-1}$ \\
\hline 1 & 0.043 & 19.0 & Presente & 6.8 & 3260 & 6.0 & 37.78 & 2086.40 \\
\hline 2 & 0.546 & 21.0 & Presente & 6.7 & 2960 & 5.0 & 338.46 & 1894.40 \\
\hline
\end{tabular}




\begin{tabular}{|l|l|l|l|l|l|l|l|l|}
\hline 3 & 0.717 & 25.5 & Presente & 7.4 & 2720 & 3.5 & 316.67 & 1740.80 \\
\hline 4 & 0.031 & 17.5 & Ausente & 7.3 & 1265 & 0.0 & 8.89 & 809.60 \\
\hline 5 & 0.683 & 20.5 & Presente & 7.3 & 4160 & 7.5 & 566.67 & 2662.40 \\
\hline 6 & 0.004 & 22.0 & Ausente & 5.7 & 1309 & 0.5 & 100.00 & 837.76 \\
\hline 7 & 0.050 & 16.0 & Presente & 7.6 & 876 & 0.8 & 37.50 & 560.64 \\
\hline 8 & 0.848 & 18.5 & Presente & 7.7 & 2920 & 1.6 & 138.10 & 1868.80 \\
\hline 9 & 0.311 & 25.5 & Presente & 7.0 & 1985 & 3.5 & 26.30 & 1270.40 \\
\hline 10 & 0.003 & 25.1 & Ausente & 7.2 & 1742 & 1.5 & 50.0 & 1114.88 \\
\hline Prom & 0.324 & 20.65 & --- & 7.07 & 2319.70 & 2.99 & 162.04 & 1484.61 \\
\hline Mín & 0.003 & 16.00 & --- & 5.7 & 876 & 0.0 & 8.89 & 560.64 \\
\hline Máx & 0.848 & 25.5 & --- & 7.7 & 4160 & 7.5 & 566.67 & 2662.4 \\
\hline *LMP & NN & 40 & Ausente & $5-10$ & NN & 2 & 125 & NN \\
\hline **LMP & NN & NN & Ausente & NN & NN & NN & 30 & NN \\
\hline
\end{tabular}

*LMP: Referencia de la NOM-001-SEMARNAT-1996; LMP: referencia de la NOM-003 SEMARNAT-1996. NN: Parámetro no normado.

Los sólidos sedimentables (SSe) variaron de 0.0 a $7.5 \mathrm{~mL} \mathrm{~L}^{-1}$ con media de $2,99 \mathrm{~mL} \mathrm{~L}^{-1}$, las estaciones 4, 6, 7, 8 y 10 quedaron dentro del límite máximo de $2.0 \mathrm{~mL} \mathrm{~L}^{-1}$ y las estaciones 1, 2, 3, 5 y 9 lo sobrepasaron. Los sólidos suspendidos totales mostraron una variación de 8.89 a 566.67 con valor medio de $162.04 \mathrm{mg} \mathrm{L}^{-1}$, el promedio puede considerarse como una concentración media en cuanto a este parámetro y aunque no se encuentra normado, es importante su determinación puesto que los elementos químicos metálicos se encuentran adheridos a estas partículas en suspensión, además que representan un problema para los sistemas de riego presurizado, en especial por goteo, problema que se puede resolver eliminando los sólidos en suspensión a través de tratamientos primarios con diversos tipos de sistemas de filtrado disponibles en el mercado como hidrociclones, filtros de arena, filtros de malla y filtros de anillas (Montalvo, 2000 y Rodríguez-Ortíz et al., 
2009) . Los sólidos disueltos totales variaron entre 560.64 a $2662.40 \mathrm{mg} \mathrm{L}^{-1}$ con un promedio de $1434.64 \mathrm{mg} \mathrm{L}^{-1}$, los valores de la estaciones 2, 3, 4, 6, 7, 8, 9 y 10 así como el promedio se clasificaron de ligera a moderada restricción y las estaciones 1 y 5 muestran una restricción severa, de acuerdo a la metodología de la FAO, el valor promedio se considera algo problemático para el riego por gravedad, pero para sistemas de riego localizado pueden generar problemas de obstrucción, sin embargo el problema se puede evitar manteniendo ligeramente ácido el pH del agua.

\section{Indicadores químicos}

En el Cuadro 6 se muestran las concentraciones de los parámetros químicos más importantes para la determinación agronómica del agua para riego agrícola Las concentraciones de grasas y aceites dieron valores de 56.0 a $1227.27 \mathrm{mg} \mathrm{L}^{-1}$ con promedio de $615.13 \mathrm{mg} \mathrm{L}^{-1}$, todas las estaciones exceden los límites máximos permisibles de las de las normas mexicanas utilizadas en este estudio de $15 \mathrm{mg} \mathrm{L}^{-1}$.

La DBO 5 mostró un intervalo de 405.27 a $7294.83 \mathrm{mg} \mathrm{L}^{-1}$ con un promedio de $3566.36 \mathrm{mg}$ $\mathrm{L}^{-1}$, rebasando en gran proporción los límites máximos permisibles de las normas en cuestión de $150.0 \mathrm{mg} \mathrm{L}^{-1}$ de NOM-001 y 30.0 de la NOM-003.

El N $\mathrm{N}_{\mathrm{T}}$ varió de 28.0 a $56.0 \mathrm{mg} \mathrm{L}^{-1}$ con una media de $34.40 \mathrm{mg} \mathrm{L}^{-1}$ no excediendo el valor normado.

La alcalinidad expresada en $\mathrm{mg} \mathrm{L}^{-1}$ como $\mathrm{CaCO}_{3}$ varió de 238.30 a $1191.50 \mathrm{mg} \mathrm{L}^{-1}$ con un promedio de $822.14 \mathrm{mg} \mathrm{L}^{-1}$, parámetro no normado y que es fundamental para determinar la calidad agronómica del agua para riego.

Entre los aniones los cloruros expresados en $\mathrm{mg} \mathrm{L}^{-1}$ variaron de 35.45 a $258.79 \mathrm{mg} \mathrm{L}^{-1}$ con valor medio de $119.82 \mathrm{mg} \mathrm{L}^{-1}$. En cuanto a la concentración de sulfatos la variación en $\mathrm{mg}$ $\mathrm{L}^{-1}$ fue de 89.54 a 288.48 con y promedio de 196.21 ambos parámetros no están normados y son de importancia fundamental para determinar la calidad agronómica del agua. 
La dureza total expresada como $\mathrm{CaCO}_{3}$ mostró valores de 232.21 a $824.74 \mathrm{mg} \mathrm{L}^{-1}$ con valor medio de $436.39 \mathrm{mg} \mathrm{L}^{-1}$. Los iones $\mathrm{Ca}^{2+}$ dieron valores de 67.33 a 211.62 con promedio de $116.07 \mathrm{mg} \mathrm{L}^{-1} \mathrm{y}$ ion $\mathrm{Mg}^{2+}$ mostró valores de 9.76 a $72.26 \mathrm{mg} \mathrm{L}^{-1}$ con valor medio de 35.74 $\mathrm{mg} \mathrm{L}^{-1}$. Para el $\mathrm{Na}^{+}$se obtuvieron valor entre 59.80 a $378.60 \mathrm{mg} \mathrm{L}^{-1}$ con promedio de $221.42 \mathrm{mg} \mathrm{L}^{-1}$ y el K${ }^{+}$mostró valores de 18.10 a $50.0 \mathrm{mg} \mathrm{L}^{-1}$ con valor medio de $38.60 \mathrm{mg} \mathrm{L}^{-}$ 1 , todos estos cationes no son considerados por la normatividad mexicana, son indispensables para la determinación agrológica del agua para riego. 


\begin{tabular}{|c|c|c|c|c|c|c|c|c|c|c|c|c|c|}
\hline \multirow{2}{*}{$\begin{array}{l}\text { Parámetros } \\
\text { Químicos }\end{array}$} & \multirow{2}{*}{ Unidades } & \multicolumn{10}{|c|}{ ESTACIONES DE MUESTREO } & \multirow{2}{*}{ PROM } & \multirow{2}{*}{$*$ LMP } \\
\hline & & 1 & 2 & 3 & 4 & 5 & 6 & 7 & 8 & 9 & 10 & & \\
\hline G y $A$ & $\mathrm{mg} \mathrm{L}^{-1}$ & 1227.27 & 1000.00 & 295.00 & 1032.20 & 792.00 & 383.00 & 56.00 & 232.00 & 783.80 & 350.00 & 615.13 & 25.00 \\
\hline $\mathrm{DBO}_{5}$ & $\mathrm{mg} \mathrm{L}^{-1}$ & 405.27 & 5268.49 & 7294.83 & 4052.68 & 5268.49 & 1621.07 & 4052.68 & 2026.34 & 405.27 & 5268.49 & 3566.36 & 150.00 \\
\hline $\mathbf{N}_{\mathbf{T}}$ & $\mathrm{mg} \mathrm{L}^{-1}$ & 28.00 & 28.00 & 28.00 & 56.00 & 42.00 & 56.00 & 28.00 & 42.00 & 28.00 & 28.00 & 36.40 & 60.00 \\
\hline $\begin{array}{l}\text { Alcalinidad } \\
\text { como } \\
\mathrm{CaCO}_{3}\end{array}$ & $\mathrm{mg} \mathrm{L}^{-1}$ & 714.90 & 714.90 & 1191.50 & 714.90 & 953.20 & 714.90 & 238.30 & 953.20 & 1072.35 & 953.20 & 822.14 & NN \\
\hline $\mathrm{Cl}^{-}$ & $\mathrm{mg} \mathrm{L}^{-1}$ & 129.04 & 153.14 & 112.02 & 35.45 & 258.79 & 54.59 & 62.39 & 64.52 & 179.38 & 148.89 & 119.82 & NN \\
\hline $\mathrm{SO}_{4}{ }^{2-}$ & $\mathrm{mg} \mathrm{L}^{-1}$ & 208.23 & 242.29 & 182.17 & 60.12 & 439.43 & 89.54 & 105.02 & 108.12 & 288.48 & 238.68 & 196.21 & NN \\
\hline$P_{T}$ & $\mathrm{mg} \mathrm{L}^{-1}$ & 49.70 & 4.29 & 0.57 & 0.04 & 5.57 & 55.78 & 0.08 & 2.82 & 49.18 & 0.69 & 16.94 & 30 \\
\hline $\begin{array}{l}\mathrm{D}_{\text {Total }} \\
\text { como } \\
\mathrm{CaCO}_{3}\end{array}$ & $\mathrm{mg} \mathrm{L}^{-1}$ & 368.33 & 520.47 & 360.32 & 344.31 & 824.74 & 432.39 & 232.21 & 448.40 & 488.44 & 344.31 & 436.39 & NN \\
\hline $\begin{array}{l}\mathrm{D}_{\mathrm{Ca} 2+} \\
\mathrm{Como} \\
\mathrm{CaCO}_{3}\end{array}$ & $\mathrm{mg} \mathrm{L}^{-1}$ & 168.15 & 408.37 & 224.20 & 232.21 & 528.48 & 376.34 & 192.17 & 312.28 & 240.22 & 216.19 & 289.8 & NN \\
\hline
\end{tabular}




\begin{tabular}{|c|c|c|c|c|c|c|c|c|c|c|c|c|c|}
\hline $\begin{array}{l}\mathrm{D}_{\mathrm{Mg} 2+} \\
\mathrm{Como} \\
\mathrm{CaCO}_{3}\end{array}$ & $\mathrm{mg} \mathrm{L}^{-1}$ & 200.18 & 112.10 & 136.12 & 112.10 & 296.27 & 56.05 & 40.04 & 136.12 & 248.22 & 128.12 & 146.53 & NN \\
\hline $\mathrm{Ca}^{2+}$ & $\mathrm{mg} \mathrm{L}^{-1}$ & 67.33 & 163.53 & 89.78 & 92.99 & 211.62 & 150.70 & 76.95 & 125.05 & 96.19 & 86.57 & 116.07 & NN \\
\hline $\mathrm{Mg}^{2+}$ & $\mathrm{mg} \mathrm{L}^{-1}$ & 48.82 & 27.34 & 33.20 & 27.34 & 72.26 & 13.67 & 9.76 & 33.20 & 60.54 & 31.25 & 35.74 & NN \\
\hline $\mathrm{Na}^{+}$ & $\mathrm{mg} \mathrm{L}^{-1}$ & 222.20 & 199.90 & 378.60 & 115.20 & 310.10 & 95.00 & 59.80 & 174.90 & 336.2 & 322.3 & 221.42 & NN \\
\hline $\mathrm{K}^{+}$ & $\mathrm{mg} \mathrm{L}^{-1}$ & 33.80 & 44.20 & 35.40 & 29.20 & 48.40 & 45.00 & 18.10 & 34.20 & 50.00 & 47.70 & 38.60 & NN \\
\hline
\end{tabular}

Cuadro 6. Concentraciones de los parámetros fisicoquímicos de las muestras de aguas residuales no entubadas en $\mathrm{mg}^{-1}$ 


\section{Indicadores microbiológicos}

Respecto al contenido de coliformes fecales, en las 10 muestras de aguas residuales analizadas, el resultado reveló una concentración $>2.4 \times 10^{6} \mathrm{CF} 100 \mathrm{~mL}^{-1}$, por lo que la calidad de agua para uso agrícola con este contenido de bacterias no cumple y sobrepasa los límites máximos permisibles establecidos en las Normas Oficiales Mexicanas NOM001- SEMARNAT-1996 (2000 CF $100 \mathrm{~mL}^{-1}$ como resultado de un análisis en una muestra simple) y NOM- 003- SEMARNAT-1997, la media geométrica en por lo menos 2 muestras simples en un mes (1000 CF $100 \mathrm{~mL}^{-1}$ para muestras de agua de reúso para servicio al público al contacto directo u ocasional).

Desde un punto de vista bacteriológico, la principal desventaja de usar agua de desecho no tratada para el riego es la presencia de bacterias, virus y parásitos que pueden representar riesgos para la salud de los agricultores y las comunidades que están en contacto prolongado con el agua de desecho y también a los consumidores de productos irrigados con esta agua (Bonilla et al., 2005; Bonilla et al., 2008; Cabrera et al., 2005; Cabrera et al., 2012; Díaz et al., 2005). Aún cuando este tipo de agua trae un gran beneficio que se refleja en un incremento en la fertilidad de los suelos, una diversificación de cultivos, también contribuye a una dispersión de organismos patógenos, en agua, suelo, aire, acuífero y en cultivos, así como una posible incorporación al suelo de sustancias tóxicas, metales, plaguicidas y residuos orgánicos con baja tasa de degradación. El tratamiento de agua es al menos en teoría la mejor opción para proteger la salud humana y se necesitan métodos de tratamiento eficaces y de bajo costo, que eliminen los patógenos pero que al mismo tiempo retengan los nutrientes presentes en el agua.

\section{Conclusión}


La clasificación agronómica las muestras de aguas residuales no entubadas arrojadas a las barrancas por algunas industrias del PI 5 de Mayo comprendió de las estaciones: 1, 2, 4, 5, 7 y 8 cuyos resultaron fueron muy heterogéneas, quedaron clasificadas de acuerdo a los indicadores de peligro de sales y de sodio como se muestra en el Cuadro 7.

\begin{tabular}{|c|c|c|c|c|c|c|}
\hline \multirow{2}{*}{ Indicador } & \multicolumn{6}{|c|}{ Estación de muestro del PI 5 de Mayo } \\
\hline & 1 & 2 & 4 & 5 & 7 & 8 \\
\hline CE & AS & AS & AS & AAS & AAS & AAS \\
\hline SE & C & C & C & C & C & C \\
\hline SP & C & C & B & C & B & B \\
\hline RAS & B & B & B & B & B & B \\
\hline CSR & C & B & C & B & B & NR \\
\hline PSP & C & C & C & C & C & C \\
\hline $\mathrm{Cl}-$ & C & C & C & C & C & C \\
\hline $\begin{array}{l}\text { Clasf. } \\
\text { RAS-CE }\end{array}$ & $\begin{array}{l}\text { AMAS } \\
\text { media } \\
\text { en } \mathrm{Na}\end{array}$ & $\begin{array}{l}\text { AMAS } \\
\text { media } \\
\text { en } \mathrm{Na}\end{array}$ & $\begin{array}{l}\text { AAS } \\
\text { baja } \\
\text { en } \mathrm{Na}\end{array}$ & $\begin{array}{l}\text { AMAS } \\
\text { media } \\
\text { en } \mathrm{Na}\end{array}$ & $\begin{array}{l}\text { AAS } \\
\text { baja } \\
\text { en } \mathrm{Na}\end{array}$ & $\begin{array}{l}\text { AMAS } \\
\text { media } \\
\text { en } \mathrm{Na}\end{array}$ \\
\hline
\end{tabular}

AAS = agua salina, AMAS = agua altamente salina

Y para la clasificación agronómica del PI Puebla 2000 que comprendió las estaciones 3, 6, 9 y 10, también los resultaron fueron muy heterogéneos, quedando clasificadas de acuerdo a los indicadores de peligro de sales y de sodio como se muestra en el Cuadro 8.

\begin{tabular}{|l|l|l|l|l|}
\hline \multirow{2}{*}{ Indicador } & \multicolumn{4}{|l|}{ Estaciones de muestreo del PI Puebla 2000} \\
\cline { 2 - 5 } & 3 & 6 & 9 & 10 \\
\hline
\end{tabular}




\begin{tabular}{|l|l|l|l|l|}
\hline CE & AAS & AS & AS & AAS \\
\hline SE & NR & C & NR & NR \\
\hline SP & C & C & C & C \\
\hline RAS & B & B & B & B \\
\hline CSR & NR & B & NR & NR \\
\hline PSP & C & C & C & C \\
\hline Cl- & C & C & C & C \\
\hline $\begin{array}{l}\text { Clasf. } \\
\text { RAS-CE }\end{array}$ & AMAS & AAS & AAS baja \\
media & baja & AMAS \\
en $\mathrm{Na}$ & $\begin{array}{l}\text { alta } \\
\text { en } \mathrm{Na}\end{array}$ \\
\hline
\end{tabular}

AAS = agua salina, AMAS = agua altamente salina

Los resultados obtenidos muestran que los efluentes de las diez estaciones de aguas residuales no entubadas que son arrojadas a las barrancas por los PI 5 de Mayo y Puebla 2000 y descargas municipales de los alrededores, son de calidad agronómica condicionada y no recomendable para la mayoría de las estaciones de muestreo.

En cuanto a las concentraciones de los parámetros que regulan las normas oficiales mexicanas, NOM-001-SEMARNAT-1996 y NOM-003-SEMARNAT-1997: la materia flotante $\left(\right.$ Promedio $=$ presente), sólidos sedimentables $(\mathrm{SSe})\left(\right.$ Promedio $\left.=2.99 \mathrm{~mL} \mathrm{~L}^{-1}\right)$, sólidos suspendidos totales (SST) (Promedio $=162 \mathrm{mg} \mathrm{L}^{-1}$ ), demanda bioquímica de oxígeno $\left(\mathrm{DBO}_{5}\right)\left(\right.$ Promedio $\left.=3566.36 \mathrm{mg} \mathrm{L}^{-1}\right)$, grasas y aceites $(\mathrm{Gy} \mathrm{A})$, $\left(\right.$ Promedio $\left.=615.13 \mathrm{mg} \mathrm{L}^{-1}\right)$ exceden en gran medida los valores máximos permisibles de las normas oficiales mexicanas..

En cuanto a la contaminación fecal originada por patógenos presentes en el agua que originan enfermedades entéricas en los seres humanos, todas las muestras de agua residuales no entubadas, rebasaron los límites máximos ermisibles por la normatividad vigente presentando concentraciones $>2.4 \times 10^{6} \mathrm{CF} 100 \mathrm{~mL}^{-1}$ 
Si bien es cierto que los resultados son muy heterogéneos para ambos parques industriales, es necesario que las prácticas que se siguen implementando por algunas industrias de los PI 5 de Mayo y Puebla 2000 de arrojar los efluentes de sus aguas residuales con escasos o nulos tratamientos de manera clandestina e indiscriminada a las barrancas sin cumplir la normatividad vigente, sea vigilada y regulada por Secretaría correspondiente porque de no ser así, seguirá siendo esto la causa de la alta contaminación de los ríos Atoyac y Alseseca y la contaminación seguirá prevaleciendo, será muy complicado el rescate de estos importantes cuerpos de agua y por ende seguirán siendo afectadas por esta contaminación las parcelas de cultivo de las zonas de Tecamachalco-Tehuacán y la de Atlixco e Izúcar de Matamoros, además del gran deterioro de la salud de los habitantes del estado de Puebla.

\section{Bibliografía}

Aceves, N. E. 1987. Los terrenos ensalitrados y los métodos para su recuperación. ISAAC, Fac. Agronomía, Dpto. Suelos y Agroquímica, LaHabana. 144 p.

Ayers, R. S. and D. W. Westcot. 1976. Water quality for agriculture. FAO, Irrigation and drainage. Paper No. 29, Roma.

Ayers, R. S. and D. W. Westcot. 1985. Water quality for agriculture. FAO, Irrigation and drainage. Paper No. 29, rev. 1, Roma. 174 p.

Bonilla, N., Cabrera C., Tornero A., Castro T. y Sánchez M. (2005). Aislamiento y cuantificación de contaminantes microbiológicos en sedimentos de la presa Manuel Ávila Camacho. En: Rev Int Contam Ambient. Vol (21) Suplemento 1: $757-762$.

Bonilla, F. M. N., Méndez, S.P., Tornero, C. M. A. y Cabrera, M. C. (2008). Calidad del agua de la presa "Valsequillo", Puebla, para su uso en el Distrito de Riego 030. En: 
Memorias del 2o Simposio Nacional Química Ambiental. Puebla, Pue. México. Septiembre 2008.

Cabrera, C., Bonilla, N., Tornero, M. y Castro, A.T. (2005). Monitoreo de Coliformes fecales y huevos de helmintos en Agua y sedimentos (lodos) de la presa Manuel Ávila Camacho. Departamento de Microbiología. Facultad de Ciencias Químicas, Departamento de Ciencias Ambientales y Agricultura. Instituto de Ciencia. Facultad de Ciencias Químicas Benemérita Universidad Autónoma de Puebla. México. Recuperado 20 de Agosto de 2011, de http://www.uaemex.mx/Red Ambientales/docs/memorias/Extenso/TA/EO/T AO-45.pdf

Camacho W. A. (2013). Solo operan 35 de 278 plantas de tratamieno. http://www.cmicpuebla.org.mx/secciones/?se=837. Consultado el 19 de mayo 2013

Díaz, R., Bonilla, N., Tornero, A., Cabrera, M., Ángeles, C., Gonzales, D. y Corona, J. (2005). Calidad del agua de la Presa Manuel Ávila Camacho utilizada para el riego de los cultivos en el Distrito de riego 030 Valsequillo. Departamento de Agroecología y Ambiente, Instituto de Ciencias de la BUAP, Colegio de Postgraduados-Campus Puebla. Facultad de Ciencias. Químicas de la BUAP, del Instituto Tecnológico de Puebla, Facultad de Ingeniería Química de la BUAP, Puebla México. Recuperado el 20 de Noviembre de 2011, de http://www.uaemex.mx/Red Ambientales/docs/memorias/Extenso/QA/EC/Q AC-03.pdf

Diario Oficial de la Federación de los Estados Unidos Mexicanos. Norma Oficial Mexicana. Proyecto de Norma Mexicana PROY-042/1-SCFI-2008. Análisis de agua Detección y enumeración de organismos coliformes, organismos coliformes termotolerantes $\quad \mathrm{y}$ Escherichia coli presuntiva. 
http://200.77.231.100/work/normas/nmx/2009/p-nmx-aa-042-1-scfi-08.pdf

Consultada el16 de mayo 2013.

Diario Oficial de la Federación de los Estados Unidos Mexicanos. Norma Oficial Mexicana NOM-001-SEMARNAT-1996 Que establece los límites máximos permisibles de contaminantes en las descargas de aguas residuales en aguas y bienes nacionales, 23 de abril 2003.

Diario Oficial de la Federación de los Estados Unidos Mexicanos. Norma Oficial Mexicana NOM-003-SEMARNAT-1997, que establece los límites máximos permisibles de contaminantes para las aguas residuales tratadas que se reúsen en servicios al público. 23 de abril 2003.

Eaton A. D., Clesceri L. S., Rice E. W., Grrenberg A. E. 2005. Stsndard Methods for the Examination of water and wastewater. Centennial Edition. $21^{\text {st }}$ Edition.

Castellanos, J. Z., J. X. Uvalle Bueno, A. Aguilar Santelisis. 2000. La calidad del Agua para uso agrícola. In: Manual de Interpretación de Análisis de Suelos y Aguas. Ed. INCAPA, 2a. Edición. pp. 158-166.

Cueto Wong, J. A., D. G. Reta Sánchez, G. González Cervantes, I. Orona Castillo y J. Estrada Ávalos. 2005. Características químicas de aguas de pozos profundos del acuífero de Villa Juárez, Durango. Agrofaz. Vol.5, num. 2. pp. 869-874.

Fernández, G. R. 1990. Algunas experiencias y proposiciones sobre recuperación de suelos con problemas de sales en México. Terra 8: 226-240.

Flores, D. A., V. Gálvez, O. Hernández, J. G. López, A. Obregón, R. Orellana, L. Otero y M. Valdés. 1996. Salinidad: un nuevo concepto. Universidad de Colima, Universidad Autónoma Metropolitana, Ministerio de Agricultura de Cuba.137 p. 
Glynn, J. H. 1999. Contaminación del agua. In: Ingeniería ambiental. Glynn, J. H. y G. W. Heinke. Segunda edición. Pearson, Prentice Hall. pp. 421-491.

Martínez Cruz, A., M. Mena y A. Noa. 1986. Residuos orgánicos de las fábricas de azúcar de caña y alcohol como mejoradores de suelos salinos. I. Efectividad en el lavado de la sales. Ciencia Agrícola, 26: 103-113.

Maas, E. V. 1984. Crop tolerance. California Agriculture, 38 (10): 20-21.

Miller, W. P. y J. Cifres. 1998. Effect of sodium nitrate and gypsum on infiltration and erosion of a highly weathered soil. Soil Science, 145: 304-309.

Mengel, Konrad and Ernest. A. Kirkby. 1982. Principles of plant nutrition. International Potash institute. Bern, Switzeralnd. 655 p.

Montalvo, L. T. 2000. Cabezal de riego. In: Fertirrigación, cultivos hortícolas y ornamentales. Coordinador Carlos Cadahía L. Mundi-Prensa, 2a edición. pp. 247-263.

Otero, L. 1993. Particularidades del intercambio catiónico de los suelos oscuros plásticos de la provincia Granma, relacionado con su manejo. Tesis doctorado en ciencias agrícolas. Ministerio de agricultura. Instituto de suelos. Cuba. 100 p. Tropical and Subtropical Agroecosystems, 10 (2009): 355 - 367367.

Palacios, V. O. y Aceves, N. E. 1970. Instructivo para el muestreo, registro de datos e interpretación de la calidad del agua para riego agrícola. 49 p.

Palacios, V. O. y Aceves, N. E. 1994. Instructivo para el muestreo, registro de datos e interpretación de la calidad del agua para riego agrícola .49 p. 
PND. 2007. Aprovechamiento sustentable de los recursos naturales. 4.1 Agua. Plan Nacional de Desarrollo 2007-2012. Presidente de México, Felipe Calderón Hinojosa. $\quad$ www.presidencia.gob.mx. Disponible: http://pnd.calderon.presidencia.gob.mx/index. php?page=agua. Fecha de consulta 18 de septiembre del 2008.

Ramalho, R. S. 1996. Tratamiento terciario de las aguas. In: Tratamiento de aguas residuales. Editorial Reverté, S. A. pp. 585-696.

Rhoades, J. D. and S. D. Merrill. 1976. Assessing the suitability of water for irrigation: Theoretical an empirical approaches. In Prognosis of salinity and alkalinity. FAO soils bulletin 31, FAO, Rome, pp. 69-110.

Stevens, D. P., M. J. McLaughlin and M. K. Smart. 2003. Effects of long-term irrigation withreclaimed water on soils of the Northerm Adelaide Plains, South Australia. Australian Journal of Soil Research, 41: 933-948.

Suarez, D. L. 1981. Relationship between pHc and SAR and an alternative method for estimating SAR of soil or drainage water. Soil ScienceSociety America Journal, 45: 469-475.

Villanueva Díaz, J. y Hernández Reyna A. 2001. Opciones productivas para sitios con problema de sales en la zona media potosina. Instituto Nacional de Investigaciones Forestales, Agrícolas y Pecuarias, Centro de Investigación Regional del Noreste, Campo Experimental Palma de la Cruz. México. Folleto técnico No. 16 